\title{
Social psychophysics: Using psychophysics to answer "social" questions with PsychoPro
}

\author{
Otto H. Maclin, M. Kimberly Maclin, Dwight Peterson, \\ Osman Chowdhry, And Priyanka Joshi \\ University of Northern Iowa, Cedar Falls, Iowa
}

\begin{abstract}
Complex social stimuli (like faces) can be studied using a methodology typically reserved for studying lights, tones, and colors: psychophysics. Given that psychophysics examines how humans detect and respond to stimuli in their environment, we can extend that to the study of how humans detect social stimuli in the environment. Using psychophysical methodology to answer "social" questions provides another dimension of experimental manipulation and control to the diverse array of methodologies already used by social psychologists. In this article, we review psychophysical methodology, provide a rationale for social psychophysics, describe an easy-touse software program called PsychoPro, for collecting psychophysical data, and present data collected using this program to examine racial thresholds that provide evidence for a cognitive gating mechanism for racial information that impacts face processing (MacLin \& MacLin, 2007, in press; MacLin, MacLin, \& Peterson, 2008).
\end{abstract}

This article provides a rationale for social psychophysics, reviews psychophysical methodology, describes an easy-to-use computerized system in Visual Basic (VB) 2005 for collecting psychophysical data, and presents data examining racial thresholds that provide evidence for a mechanism for gating racial information (MacLin \& MacLin, 2007, in press; MacLin, MacLin, \& Peterson, 2008). Furthermore, we discuss how the long tradition of psychophysics can be extremely useful in exploring current research questions in areas beyond perception that include complex stimuli relevant to social psychology.

We use the term social psychophysics to describe research that uses psychophysical methods to study "social" questions. Using psychophysics methodology to answer social questions is not a new practice, but it is underutilized. It adds another dimension of experimental manipulation and control to the diverse array of methodologies already used by social psychologists. As psychophysics has been used in areas such as perception and color vision to unravel the underlying perceptual mechanisms, so too can psychophysics be used to help unravel complex social-cognitive phenomena.

In particular, we present data supporting a theory that racial classification has evolved to facilitate the identification of persons belonging to out-groups as well as to in-groups, allowing for different cognitive processing depending on the outcome of the racial classification. Using psychophysical methods, we have been able to further explore the cognitive processes involved in, and social effects of, racial categorization.

\section{Psychophysical Methods}

Psychophysics examines the relationship between the physical world and our perception of it. Early emphasis of psychophysics was on determining sensory thresholdsthe point where a stimulus or change in stimulus is detected $50 \%$ of the time (Fechner, 1860/1966; Snodgrass, 1975). Thresholds can be the point at which a weak stimulus is detected (absolute threshold) or the point at which a strong stimulus is no longer detected (terminal threshold). Being able to detect signals in the environment allows for exploring whether a sensory stimulus is changing on a continuum or in discrete steps (Gescheider, 1997). Psychophysicists have developed several experimental methods to establish thresholds and evaluate signal detection. A simple example of measuring thresholds would be for luminance intensity. At what point can a light be detected? At what point can a light no longer be detected? Psychophysical methods are used to answer these perceptual questions and can be used to answer other social questions, such as "Is this person Caucasian?" or "Is this person African American?"

\section{Social Psychophysics}

Social psychologists have long been methodologically creative in their study of complex social phenomena. Social psychologists have borrowed methodologies from other content areas in psychology when their use will assist in uncovering new aspects of social thought or behavior. Contributions from cognitive psychology and neuroscience in particular have led to the areas of social cognition and social neuroscience, respectively.

Another area that can be useful for social psychologists is psychophysics. Given that psychophysics is the study of how humans detect events and stimuli in their environment, social psychophysics is the study of how humans detect social events and stimuli in the environment (Ge-

O. H. MacLin, otto.maclin@uni.edu 
scheider, 1997). Instead of lights, tones, and colors, such social stimuli as faces, situations, language, and concepts can be studied using psychophysics.

The term social psychophysics is not new (see, e.g., Davis, 1963); however, the label has often been applied to research that only very broadly uses aspects of psychophysics. Social-psychological research that uses psychophysics includes studies comparing a socialpsychological variable (e.g., stage fright as mediated by the intensity, immediacy, and number of persons present, Jackson \& Latané, 1981; dyadic communications, Roby \& Budrose, 1966) with a psychophysical variable (e.g., lightbulb luminance, Jackson \& Latané, 1981; Roby \& Budrose, 1966), and those quantifying the type of stimulus presented and recording participants' responses (e.g., communication studies, Meltzer, Morris, \& Hayes, 1971; dissonance, Wilson \& Russell, 1966; social climate, Davis, 1963; nonverbal communication, Kurzban, 2001). Other studies use psychophysical methods to study social psychological phenomena without making direct reference to psychophysics (e.g., Krantz, Ballard, \& Scher, 1997, used magnitude estimation to study perceptions of attractiveness and the waist-hip ratio; Corneille, Huart, Becquart, \& Brédart, 2004, studied accentuation effects of racial characteristics; Stern, Mullennix, Corneille, \& Huart, 2007, examined discrimination tasks of pitch and speech). Thurstone's (1931) methods for scaling social attitudes have been referred to in psychophysical terms, if not by the researchers themselves (Baker, 1977; Dercole \& Davenport, 1974; Stevens, 1936; Thurstone, 1931; Upshaw, 1962). As Gescheider (1997) noted, "Advances in psychophysical methodology are no longer restricted in their usefulness to the study of sensory thresholds, but instead may provide powerful techniques for how people make decisions about environmental events in general" (p. 166).

\section{Race, Racial Categorization, and the Cross-Race Effect}

Another social-psychological variable that lends itself to psychophysical methodology is race: Because race is expressed in the human face, the face can be used to study various social-psychological topics, such as racial categorization. Social psychologists know a great deal about racial categorization in the form of stereotypes, prejudice, and the cross-race effect, to name a few topics. Although much is known about these topics, the underlying processes are still poorly understood.

Of particular interest to us is the cross-race effect. It occurs when members of one race have difficulty recognizing members of another race (Malpass \& Kravitz, 1969; Meissner \& Brigham, 2001). Errors associated with the cross-race effect occur in a different pattern than errors occurring when same-race faces are involved. A disproportionate number of false alarms occur; that is, otherrace faces are believed to have been seen before, when in actuality they are new, unseen faces. This presents a problem in the legal system when witnesses attempt to recognize a perpetrator of a race different from their own, increasing the possibility for misidentification and subsequent false conviction (Innocence Project, 2008).

Early attempts to explain the cross-race effect focused on social circumstances, such as negative racial attitudes and a lack of contact with members of other races (Malpass \& Kravitz, 1969). More recent attempts at explaining the cross-race effect posit a deficit model wherein other-race faces are poorly encoded (Chiroro \& Valentine, 1995; Sporer, 2001; Valentine, Chiroro, \& Dixon, 1995). MacLin and MacLin (2007, in press; MacLin et al., 2008) have argued that the cross-race effect does not occur due to problems with encoding; rather, the human brain never evolved to optimally encode members of other races for later recognition. The brain instead evolved to quickly categorize faces as same-race/in-group or other-race/outgroup members and to direct the facial information to appropriate brain areas for later processing (Phelps et al., 2000).

\section{Cognitive Gating Mechanism for Racial Markers}

If we are to understand stereotypes, prejudices, and cross-racial identifications, we must understand the basic cognitive processes involved in racial categorization and identification. MacLin and MacLin (2007, in press; MacLin et al., 2008) have argued for the existence of a cognitive gating mechanism tuned to racial markers that is activated early in the face-recognition process. The brain has the propensity to detect very early in the time course of perception the presence of threatening objects, such as other-race faces (Correll, Urland, \& Ito, 2006). On the basis of physiological data, it is likely that the process begins as early as $100 \mathrm{msec}$ after viewing an other-race face, and $200 \mathrm{msec}$ after viewing a racially ambiguous face (Ito, Thompson, \& Cacioppo, 2004; Willadsen-Jensen \& Ito, 2006). MacLin and MacLin (2007, in press; MacLin et al., 2008) have proposed that as a default, same-race faces pass through this gating mechanism undetected, to be processed through typical face-recognition stages (see Bruce \& Young, 1986). However, if the gating mechanism detects a racial marker (e.g., hair, skin tone, eye color), facial information is instead routed to other brain areas, such as the amygdala (Hart et al., 2000; Phelps et al., 2000; Phelps \& Thomas, 2003), and to distinctly separate areas of the fusiform face area (Golby, Gabrieli, Chiao, $\&$ Eberhardt, 2001) for processing different from that of same-race faces.

According to MacLin and MacLin (2007, in press; MacLin et al., 2008), this differential processing has ecological validity. Same-race faces representing in-group members are likely processed for their social cues and for individuating features for future recall and recognition, since it is important to know who is who and what their social standing is within a person's group. However, other-race faces representing out-group members likely pose potential threats (to resources, safety, and mating). Processing other-race faces for individuating information may then come at a cost to survival. Therefore, we argue that a gating mechanism was selected out through evolutionary pressures to help individuals avoid other humans 
who might pose a threat by extracting different information from the environment regarding group membership.

To answer questions that arise from this theory, we developed a procedure whereby we could isolate and study the influence of racial markers on the cognitive processing of faces using a computer program (designed to conduct psychophysical studies) and a method of stimulus preparation (morphing images) that would allow us to study systematically the effects of racial markers on the perception of faces. Methods that were once reserved for studying physical stimuli such as luminance, color, and other physical phenomena that can be presented on a continuum (Snodgrass, 1975) can be applied to more socially complex stimuli such as faces.

\section{Faces As Social Stimuli}

As mentioned previously, stimuli relevant to social psychologists tend to be complex and sometimes difficult to quantify. One type of stimulus that is widely used in social psychological research is the human face. Images of faces are used to convey emotion, status, health, attractiveness, and deviance (Phelps et al., 2000; Zebrowitz, 1998). Faces are one of the most important ways that we gather social information about other people, providing information (though not always accurately) about attractiveness, race, gender, age, and personality characteristics. Thus, it is not surprising that the face is often used in socialpsychological research.

Faces are desirable stimuli but can pose control problems. MacLin and Malpass (2001) addressed this issue in their study using ambiguous-race faces (ARFs) to examine the cross-race effect. They were able to manipulate false alarms by changing a single feature acting as a racial marker on otherwise identical faces. Racial markers are any salient attribute that can be used to categorize an individual as an out-group member (e.g., hair, skin tone, eye color; see Bernstein, Young, \& Hugenberg, 2007, for examples). The key finding was that once race was determined (early in the perceptual process), an entirely different cognitive processing occurred, resulting in differential categorization of otherwise identical stimuli (with just the hair being different). Later, MacLin and Malpass (2003) published the ARFs as a visual illusion demonstrating that the skin tone of the facial images was perceived as darker when an African American hair marker was used. This effect was later replicated (Levin \& Banaji, 2006). This advance in stimulus development was critical for researchers who needed to rule out that effects were not due to invariant properties of the face.

Any researcher using facial stimuli recognizes the importance of (and struggle involved in) finding or creating high-quality facial images. The more realistic the stimuli, the better able we are to test theories regarding face processing in the laboratory. The facial composite system used in the original ARF studies was a breakthrough in terms of stimulus control. The faces, however, looked more like high-quality pencil portraits than photographs of faces. Another method for developing facial stimuli is the use of morphing techniques. Current morphing tech- nology allows for stimulus control, while creating realistic, photograph-quality faces.

\section{Creating Faces on a Continuum Using Morphing Techniques}

Psychophysical methods require that stimuli be continuous. If one uses available morphing techniques, faces can be represented on a physical continuum, thus allowing them to be examined via psychophysical methods (see Steyvers, 1999; Webster, Kaping, Mizokami, \& Duhamel, 2004).

We created a stimulus continuum of 51 faces derived from two "parent" faces using a morphing program called FantaMorph (Abrosoft, 2008), where parent faces are the two original starting faces (Chowdhry, Peterson, MacLin, \& MacLin, 2007; see the present Figure 1). Morphing programs allow for the transformation of one image into another image, using a feature-based algorithm (Beier \& Neely, 1992). This transformation begins with one starting image $(0 \%)$ and "morphs" along a continuum into another starting image $(100 \%)$, the middle of which consists of $50 \%$ of the transformation of both images (Abrosoft, 2008). Therefore, if an African American face is used as the starting parent and a Caucasian face is used as the terminating parent, a face located at the $25 \%$ stimulus continuum point will mathematically consist of $75 \%$ African American features and 25\% Caucasian features (see Steyvers, 1999, for a review of morphing).

FantaMorph is relatively inexpensive and easy to use. It allows the user to export the morph as an AVI movie or as an image sequence, with the number of images generated determined by the user (up to 999 images). For our purposes, we used the 51-image setting, so that each image had a $2 \%$ difference from the previous face (e.g., Image 26 represented the $50 \%$ average). The morph located at the $50 \%$ continuum mark was mathematically half African American and half Caucasian; however, this is not to say that the face located at the $50 \%$ point was perceptually at the racial midpoint (a significant problem for researchers
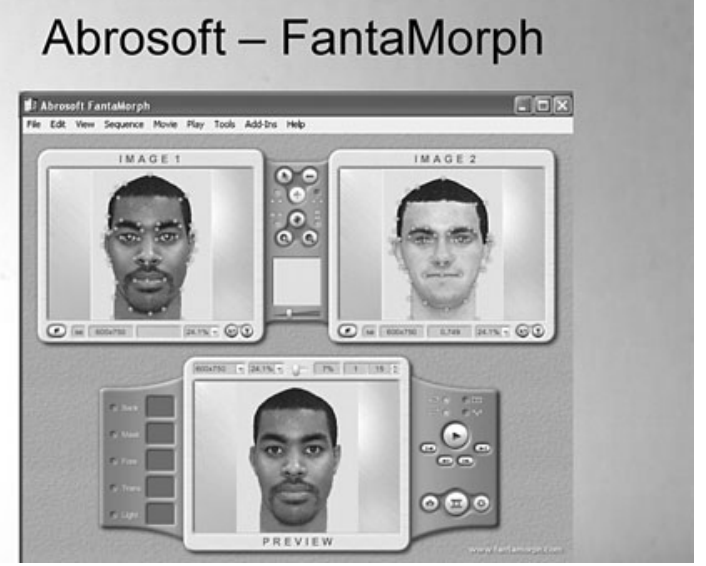

Figure 1. Morphing program interface. 
who use and consider the $50 \%$ face as ambiguous to race; Chowdhry et al., 2008).

\section{PsychoPro: A Program for \\ Collecting Psychophysical Data}

To display the stimuli and collect observer responses, we developed a computer program written in VB 2005 to collect measurements using psychophysical methods. VB has been recommended for use in writing programs for conducting research in psychology (Dixon \& MacLin, 2003; MacLin, Dixon, \& Jackson, 2007). PsychoPro consists of one VB form, although additional forms can be easily added to present instructions to the observers and record demographics. In the program, there are two timer controls. One timer control is used to display a visual mask that is presented between each stimulus presentation to retard any visual persistence. The other timer control is used to regulate the amount of time an adapting stimulus is displayed when adaptation is part of the procedure being used. Comments and instructions are embedded throughout the actual computer code within the edit level of the form, to guide and assist with modifications to the code, depending on the goals specific to the study being conducted. For instance, if the timer object previously mentioned, which is below the main form of the computer program, is doubleclicked, the code corresponding to the timer object within the edit level of the form will appear. Above the actual code, comments that are "remarked out" and appear in a green font guide the user as to the specific function of each of the objects that exist on the main form. To enter the edit level (e.g., the code) of the project, the user must simply double-click on the existing form or objects within the form. Once a form or an object within the form is doubleclicked with the computer mouse, the existing code corresponding to the specific subroutines that exist for each object embedded within the form will appear and can be edited, depending on the type of stimuli, file extensions, and instructions being used for a specific experiment utilizing a specific method.

Depending on the method being used, PsychoPro will display an image and wait for the observer's response (although a simple change in the VB code can remove the image after a specified amount of time). Observers respond by clicking on buttons located below the facial image. Once an observer response is made, the button used is recorded, along with the stimulus value; the visual mask then briefly appears (presentation time can be modified during design time) and is then replaced with the next stimulus. Instructions/questions can be programmed directly into the VB 2005 code to appear directly above the stimulus - for example, "Is this person Caucasian?" Below the stimulus, two response buttons will be displayed that can also be programmed directly into the VB code. When PsychoPro starts, the left/right positions of the buttons are randomized to prevent any possible bias in button position preference. In our example in Figure 2, we used "Yes" and "No" as button text. When the observer clicks on the button presented during runtime, the actual text "Yes" or "No" is written to an output file somewhere
Is this person Black?

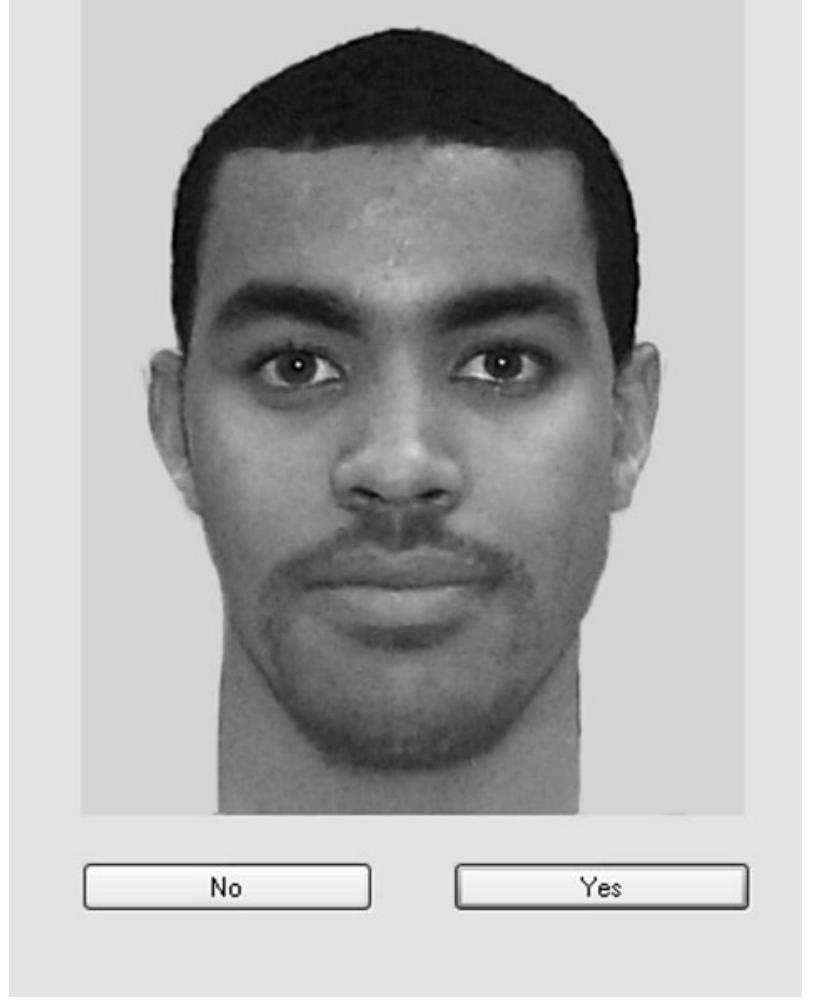

Figure 2. PsychoPro interface.

within the computer being used, the location of which is specified by the user within the computer code found within the edit level of the form (e.g., written to a Notepad file with the extension ".txt," stored within the "c:l" drive), allowing the researcher to know exactly what the stimuli and responses were and where those participant responses are stored within the computer being used. The user may also alter the code referring to the output file to either append or overwrite each of the responses made by each participant (for specific instructions, see MacLin et al., 2007). The data recorded by the program are stored within text files delimited with commas for easy importing into programs such as Microsoft Excel. Additionally, exporting data from a text file and importing them into a program such as Microsoft Excel allows the researcher to organize data for individual participants, if desired, using multiple worksheets within one spreadsheet.

PsychoPro can be used for a variety of psychophysical methods, including the method of adjustment, method of limits, method of constant stimuli, and staircase method. All methods involve the two-button response option and allow for the use of an adaptation procedure. As previously mentioned, the VB code for PsychoPro is well documented with notes on how to change existing parameters during 
design time. During design time, the researcher can indicate the method to be used, the question asked of the observer, the button text, the stimulus set to be used, the number of stimuli in the stimulus set, the directory, the name of the output file used to store the data, and whether or not the procedure involves adaptation.

Method of adaptation. If the procedure involves adaptation, PsychoPro can be changed during design time to indicate which adapt image will be used, how long the initial adaptation phase will be, and how long each topup will take (top-ups involve the brief presentation of the adapt stimulus so that the observer remains in a constant state of adaptation to the adapt stimulus and not to the properties of the testing stimuli being presented; see MacLin \& Webster, 2001). In an adaptation study, each participant completes two stimulus phases: a preadapt phase to record baseline performance, and a postadapt phase to measure the change resulting from the manipulation. During the preadapt phase, the program is designed to display a neutral gray image matching the gray background of the VB form so that all temporal aspects are held constant across each phase.

Method of adjustment/limits. With method of adjustment (descending trials), the observer adjusts the stimulus intensity down until he or she reports no longer detecting it. With ascending trials, the observer begins with a weak stimulus and systematically adjusts it upward until it is detected. Data points from ascending and descending trials are then averaged to determine a threshold value. The method of limits is similar, except that the experimenter adjusts the stimulus properties. One problem with the method of adjustment and the method of limits is that observers can bias their reporting by anticipating the approaching threshold; in these situations, the method of constant stimuli can be used. When the method of adjustment is used, the initial instruction might be "Adjust the face either darker or lighter until the face looks Caucasian." Response button text would include the words "Darker" and "Lighter" on each of two buttons, with the faces being adjusted according to the observer's response to each stimulus. When the stimulus is adjusted to the observer's satisfaction, the observer can then click on a third button (e.g., "Finished"). The text of this third button can also be modified during design time.

Method of constant stimuli. With the method of constant stimuli, there is no systematic presentation of the various stimulus levels. The stimulus values are presented randomly and the observer reports the stimulus presence or absence allowing a "frequency of seeing curve" (Boynton, 1984), which provides a monotonic function with the change in stimulus values. Probit analysis can then be used for curve fitting (Finney, 1947). Lastly, the number of observations needed for the method of constant stimuli can be problematic. If the method of constant stimuli is being used, all facial images within a given stimulus continuum set are randomized and exhibited one at a time until all faces are presented within each phase. If the question "Is the face African American?" is presented and either the "Yes" or "No" button is clicked, the observer's response is recorded to an output file specified by the user and the next image in the random sequence is displayed. During design time, the number of presentation phases can be specified by the user within the edit level of the form that displays the code. We typically use no more than 10 phases (in an attempt to minimize observer fatigue), which results in rating each face 10 times, for a total of 510 ratings (if using 51 faces within a given stimulus set). Increasing the number of phases allows the researcher to gather a relatively large amount of data from each participant. Note that once all faces within the stimulus continuum set are displayed, the stimulus set is rerandomized and displayed until all phases are complete.

Staircase method. The staircase procedure involves sampling points on either side of the threshold and then averaging those values to derive the threshold. The staircase procedure is similar to the limits method in that by using a staircase, stimulus values are presented for the observer to report. If the observer reports the stimulus present, its value is adjusted downward. If the observer cannot report the stimulus present, its value is adjusted upward. Each change in the direction of adjustment is a "reversal." The point at which the reversal occurred is recorded. After a fixed number of reversals, the experiment terminates and the reversal points are averaged to determine the stimulus threshold. Using the staircase method in PsychoPro, the initial question might be "Is the face Caucasian?" As with the method of limits, if the observer responds "No," the program will adjust the stimuli toward the Caucasian end of the continuum and continue to do so with each "No" response. At some point, the stimulus presented will be perceived as Caucasian and the observer will respond "Yes." The selection of the stimuli will reverse toward selecting a face toward the African American end of the continuum. Each reversal and corresponding stimulus value at which the reversal occurs are recorded until a predetermined number of reversals has been met (the number of reversals can be specified at design time). When the predetermined number of reversals is obtained, the program records the response and terminates.

Using morphed stimuli. Regardless of the method used, the response buttons used in the different methods perform in a similar manner: They adjust both (1) the stimulus value along the continuum and (2) how the stimuli are presented. For example, consider examining a stimulus continuum that includes facial stimuli exported as current frames (saved as a ".bmp" or ".jpg" image) from percentages of a morph movie created using FantaMorph (Abrosoft, 2008) by morphing a Caucasian face with an African American face. If when examining the above-mentioned stimulus continuum using the method of limits, the observer is asked the question "Is this person Caucasian?" and responds "Yes," the stimulus will be adjusted by the program, away from the Caucasian end of the continuum and toward the African American end. The new stimulus presented will be a face exported from a certain percentage of the morph closer to the African American end of the stimulus continuum. The number of steps used when 
advancing a face can be altered during design time. This continues until the observer indicates a "No" response. At this point the stimulus will be adjusted away from the African American end of the continuum and toward the Caucasian end of the continuum, which will then present a new stimulus face, which can be created by exporting current frames from percentages of the morph movie, closer to the Caucasian end of the continuum.

User interface. PsychoPro includes a control panel with a variety of buttons that correspond to specific psychophysical methodologies. If clicked, the button will take the user to the corresponding form in VB, with parameters to be set by the individual user. When using the method of constant stimuli, for example, the user will see text boxes with instructions about uploading stimuli and instructions specifying output file extensions and locations, and this will allow the user to indicate whether adaptation will be used. Depending on the method used, the user may specify the amount of time each stimulus will be presented and whether the stimulus will appear or disappear after a response is made by a participant or simply after a user-specified amount of time. Once the user provides the information specific to each methodology, the program is ready to be used by participants. PsychoPro is available for academic purposes from the first author. System requirements include Microsoft Visual Studios 2005 equipped with VB (see MacLin et al., 2007).

\section{Other Psychophysics Software Programs}

Several psychophysics programs for computers are available for the researcher. Early computer programs used non-psychological-specific programs to create psychophysics experiments. Anstis and Paradiso (1989) used The Director (The Right Answers Group), a program with BASIC-like language, to create visual psychophysics experiments on the Amiga computer systems. Wenderoth (1990) described methods of creating visual psychophysics without using programming languages for use in pilot testing, class demonstration, and investigation. Wenderoth used the Deluxe Paint III (Electronic Arts) program to create the Poggendorff illusion, the Müller-Lyer illusion, the Ponzo illusion, simultaneous contrast, and variable angles. However, these software programs are limited to fairly simple images (e.g., lines; Wenderoth, 1990) or 3-D images (Ward \& Liu, 2005), or to specific procedures (e.g., the staircase method; Anstis \& Paradiso, 1989).

The Psychophysics Toolbox (Brainard, 1997; Pelli, 1997 ) is widely used and well documented. It is useful for running sensory and perceptual experiments, which require temporal, color, and spatially related stimulus presentations. The Psychophysics Toolbox has been used in face and object recognition, thresholds, color matching, visual search, and motion detection (Harley \& Loftus, 2000). It serves as an interface between MATLAB (MathWorks, Inc.) and video display hardware. It is free but does require MATLAB (approximate cost: \$500).

\section{Using PsychoPro to Study Racial Categorization}

The data presented here provide an example of the program's use from a pilot study conducted in our laboratory on the role of racial markers on perception of faces. In particular, we were interested in how and where racial categorization shifts when rating African American and Caucasian faces that are morphed to create facial stimuli on a continuum. In this manner, the $50 \%$ morph based on the Caucasian racial marker will mathematically represent both races; however, for every face in the stimulus set, the hair will be held constant, with all faces expressing the Caucasian racial marker. Now the $50 \%$ morph (with the Caucasian racial marker) should be more likely to be perceived as the same race to Caucasian observers, in that the marker will shift the distribution of faces appearing Caucasian away from the Caucasian parent face. This will have the effect of expanding the number of acceptable Caucasian faces.

The method of constant stimuli and the staircase method were implemented using PsychoPro. We first collected data from a trained observer, and then followed up with observations from 2 naive observers. We present data from 1 trained observer to demonstrate how the program works and how the data can be represented (the data from the 2 naive observers were consistent with those from the trained observer).

\section{METHOD}

\section{Observer}

A trained observer from our laboratory participated in this study.

\section{Stimuli}

A stimulus continuum of 51 faces was created using FantaMorph (Abrosoft, 2008). Two stimulus continua were created using two parent faces: an African American face as the beginning face, located at the $0 \%$ point on the stimulus continuum, and a Caucasian face as the terminating face, located at the $100 \%$ point on the stimulus continuum (Chowdhry et al., 2007).

To examine the effects of racial markers on face processing, we need to hold the racial marker constant across all faces representing the continuum. Using Adobe Photoshop, we copied the hair from the Caucasian parent face and pasted it on the African American parent face (see Figure 3). The racial marker-unaltered (center column, Figure 3) is simply the combination of the original African American parent image morphed with the original Caucasian parent image, without the manipulation of hair. The hair in the $50 \%$ child in the middle cell is the product of the pixel coordinates of the hair features from the unaltered, starting African American parent image combined with the Caucasian parent unaltered, starting image. One stimulus set consisted of faces with hair from the African American parent face, and the other consisted of faces with hair from the Caucasian parent face.

\section{Apparatus}

The computer program PsychoPro was used to display and collect data. The method of constant stimuli feature was used, and during another session, the staircase method was used. All stimuli and instructions were displayed on a color monitor.

\section{Procedure}

The observer worked independently on a single computer workstation. The observer was given screen instructions that a face would be displayed on the monitor, and that it was the observer's task to determine whether the face was Caucasian (or African American) by clicking on the corresponding buttons "Yes" or "No" using the mouse; the observer was told that there was no correct or incorrect answer. Presentation order of the stimuli was counterbalanced. Once one set of faces was rated, the observer took a 10-min break and then rated the other set of faces (African American or 


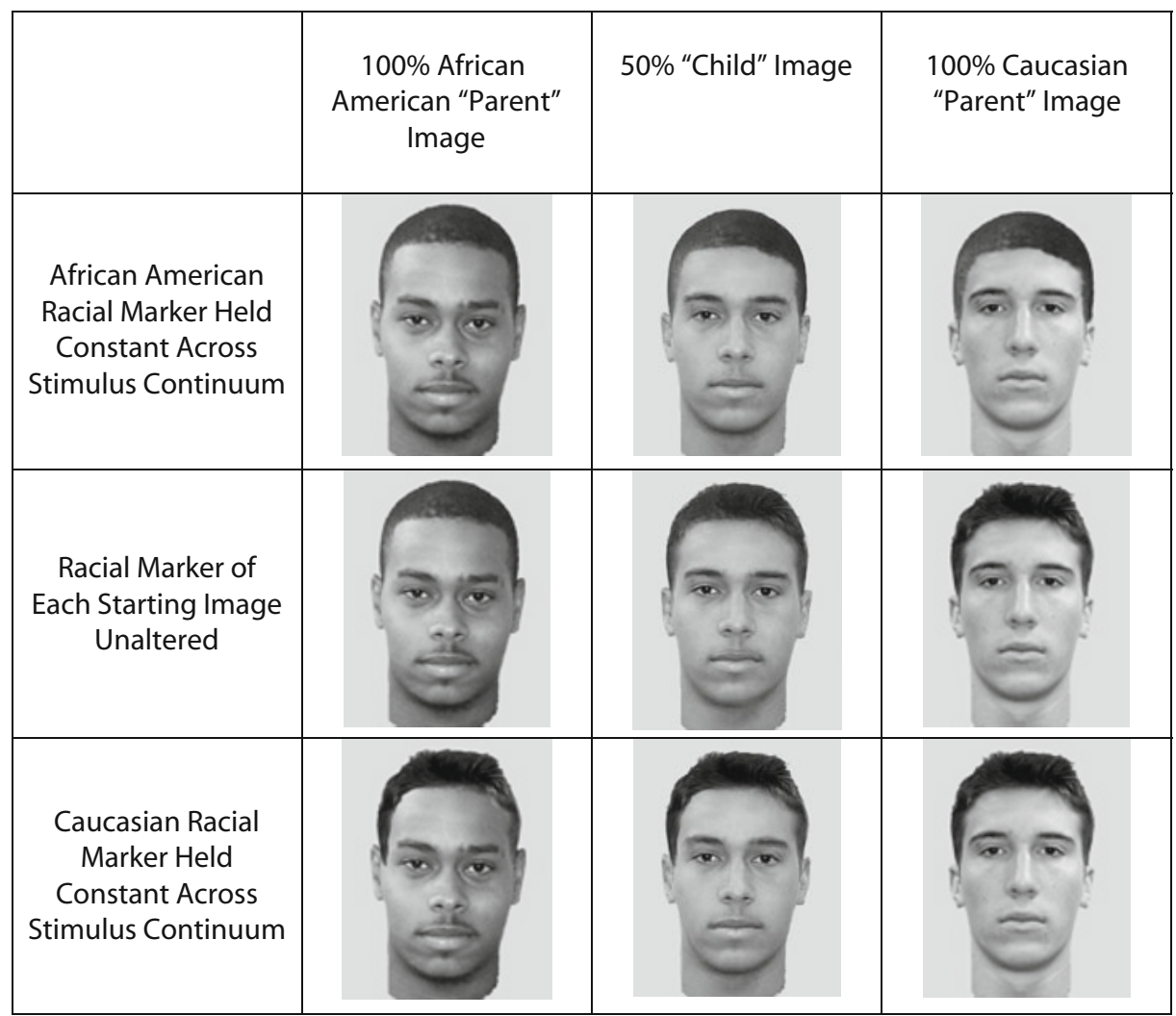

Figure 3. Parent faces showing original, African American, and Caucasian racial markers.

Caucasian). Another session was conducted in which the staircase method was used.

\section{RESULTS}

Psychophysical data are presented graphically according to their method, generally resulting in a psychophysical function (Figure 4). Recall that for the staircase method, if the observer reports the stimulus present (in this case, reports "Yes"), the face is adjusted downward. If the observer indicates "No," the face is adjusted upward. Each change in

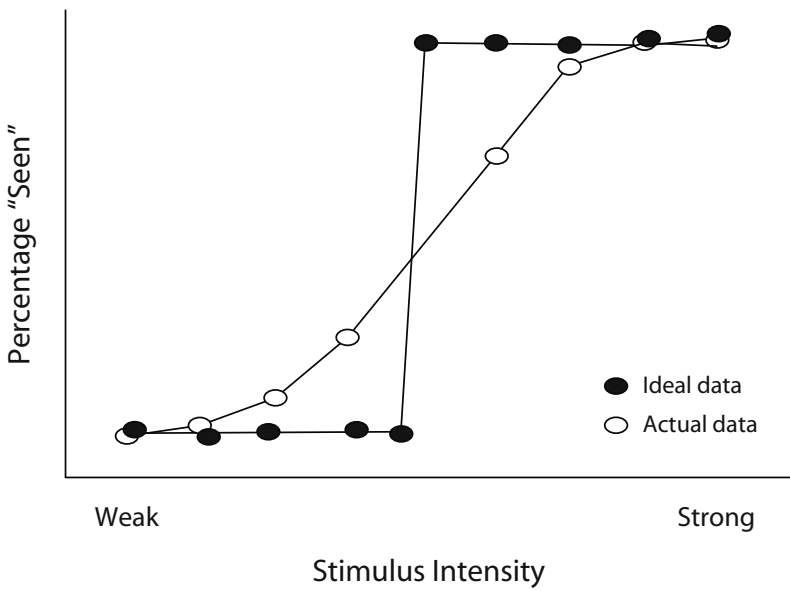

Figure 4. Psychophysical function of stimulus intensity. the direction of adjustment is a reversal. The point at which the reversal occurred is recorded. Once the observer recorded 20 reversals, the session ended. The reversal points are averaged to determine the stimulus threshold. The curve for the staircase method is sharp (thus the name), due to averaging of the reversals (Figure 5A).

For the method of constant stimuli, the various morphed faces are presented randomly and the observer reports the stimulus presence or absence, allowing for the production of a frequency curve that shows the threshold. The method of constant stimuli demonstrates a more sloping curve showing the area of the curve where faces were sometimes coded as African American and sometimes coded as Caucasian (Figure 5B).

Both types of curves allow one to see which faces were always rated as African American or Caucasian (the uppermost and lowermost, completely flat sections), as well as showing the range of faces that were more ambiguous as to race. In both cases, one can see that the $50 \%$ morph in face is not considered ambiguous at all, and that the racial categorization reliably shifts, creating in-group and outgroup faces depending on the racial marker present.

\section{DISCUSSION}

These data support the theory that there is a gating mechanism that is tuned to racial information, in such a way that racial classification alters the processing of faces on the basis of group membership. Out-group faces are 
A

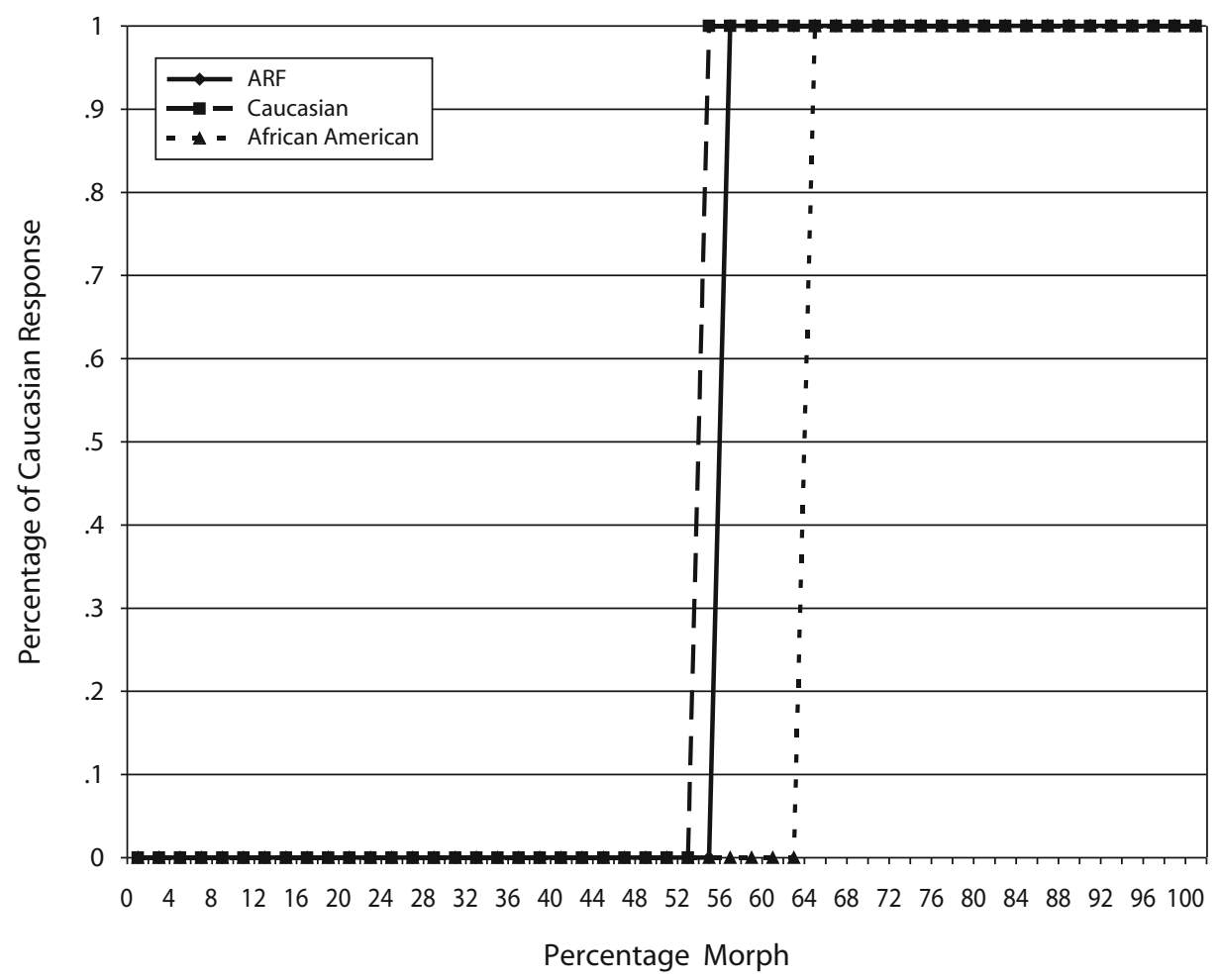

B

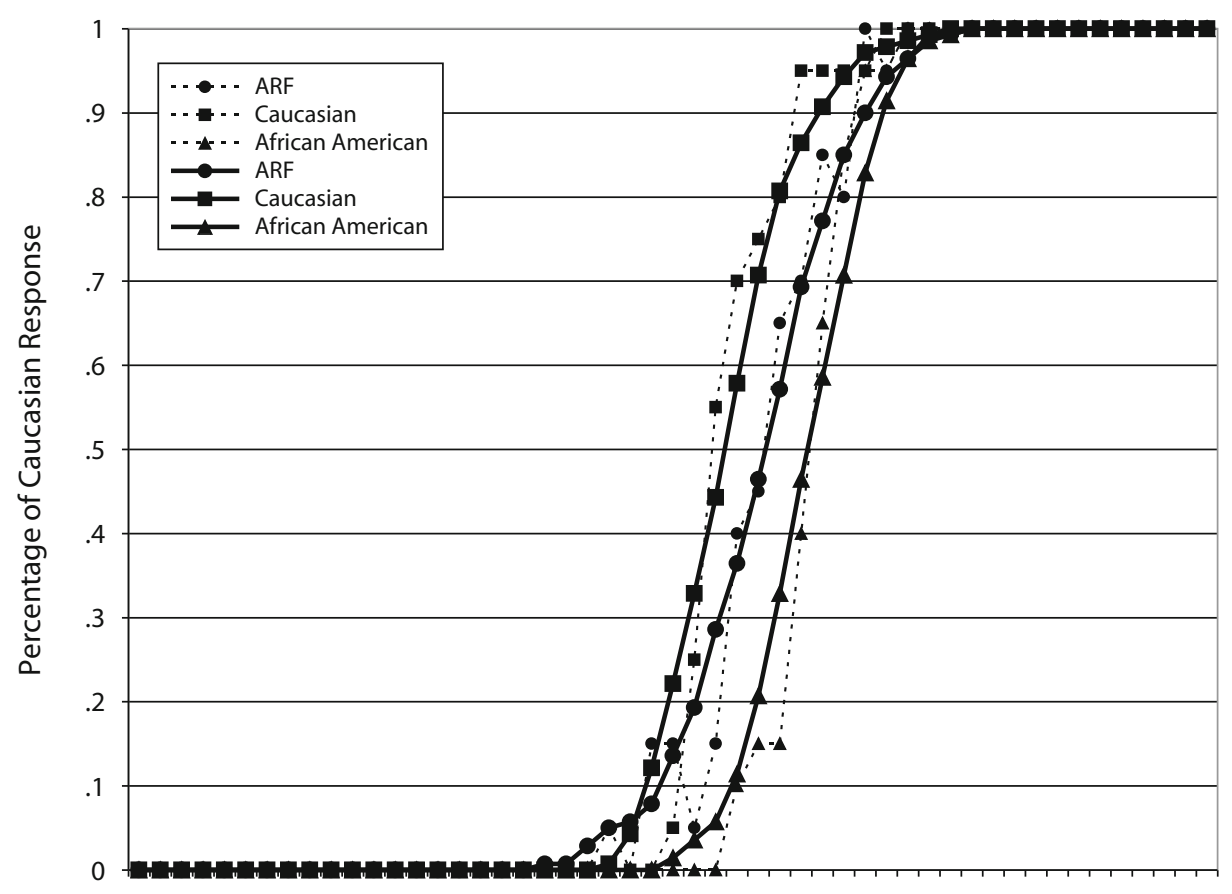

$\begin{array}{llllllllllllllllllllllllll}0 & 4 & 8 & 12 & 16 & 20 & 24 & 28 & 32 & 36 & 40 & 44 & 48 & 52 & 56 & 60 & 64 & 68 & 72 & 76 & 80 & 84 & 88 & 92 & 96 & 100\end{array}$

Percentage Morph

Figure 5. (A) Data from the staircase method for observer M.K.M. (B) Data from the method of constant stimuli for observer M.K.M. ARF, ambiguous-race face. Dashed lines are actual data; solid lines are averaged data. 
processed for threat, whereas in-group faces are processed for social properties (e.g., affect, status, later recognition; Smith \& Zárate, 1990; Zárate \& Smith, 1990). Our data suggest that a racial marker, such as hair, triggers the racial categorization process, and that the perceptual system facilitates the categorization process by erring on the side of excluding potential out-group members. These data also show that faces on a continuum can be used as psychophysical stimuli, and yield psychophysical functions similar to those for sensory stimuli (see Figure 4).

\section{Conclusions}

Psychophysics is well established and historically important to the discipline of psychology, and can be used effectively in research areas beyond sensory perception. We suggest that social psychologists can benefit from understanding the psychophysical properties of social stimuli such as faces, and that by doing so can aid in unraveling complex social-cognitive phenomena.

Furthermore, using psychophysics methodology to answer social questions provides another dimension of experimental manipulation and control to stimuli presentation and response capture. In particular, using PsychoPro can assist the researcher in implementing psychophysical methodologies in a relatively easy and inexpensive way. By presenting data on racial thresholds, we were able to demonstrate the type of information that these types of studies yield. Furthermore, psychophysical research allows for few participants to be used in data collection. This allows for researchers to use trained observers to test the efficacy of a data-collection method, pilot-test stimuli, and quickly test theoretical questions. Psychophysical data are routinely graphed to show effects. Once a phenomenon is demonstrated this way, PsychoPro can be used for data collection using naive observers (in other words, traditional participants) in order to continue to demonstrate effects and employ inferential statistics.

Finally, we have demonstrated that a continuum of morphed faces operates as psychophysical stimuli, lending itself nicely to psychophysical methodology. In addition, the data provide evidence for a gating mechanism for racial information that impacts face processing (MacLin \& MacLin, 2007, in press; MacLin et al., 2008). Psychophysics provides another level of understanding of racial categorization by showing us the thresholds of the categories, which ultimately may prove more interesting (and useful) than studying the categories themselves. Using the tools that psychophysical methodology offers in a user-friendly program allows us to quickly test our theoretical propositions, move forward in pursuing additional research questions (e.g., the role of skin tone in racial categorization; Joshi, Peterson, MacLin, \& MacLin, 2007), and focus our larger data-collection efforts on further explorations into the functions of this face-processing mechanism.

\section{AUTHOR NOTE}

We thank two anonymous reviewers for very helpful comments on earlier drafts of this article. Correspondence concerning this article should be addressed to O. H. MacLin, Department of Psychology, University of Northern Iowa, Cedar Falls, IA 50614 (e-mail: otto.maclin@uni.edu).

\section{REFERENCES}

ABRosoft (2008). Abrosoft FantaMorph. Retrieved March 20, 2007, from www.fantamorph.com.

Anstis, S., \& Paradiso, M. A. (1989). Programs for visual psychophysics on the Amiga: A tutorial. Behavior Research Methods, Instruments, \& Computers, 21, 548-563.

BAKER, P. M. (1977). On the use of psychophysical methods in the study of social status: A replication, and some theoretical problems. Social Forces, 55, 898-920. doi:10.2307/2577561

Beier, T., \& Neely, S. (1992). Feature-based image metamorphosis Computer Graphics, 26, 35-42. doi:10.1145/142920.134003

Bernstein, M. J., Young, S. G., \& Hugenberg, K. (2007). The crosscategory effect: Mere social categorization is sufficient to elicit an own-group bias in face recognition. Psychological Science, 18, 706712. doi: $10.1111 / \mathrm{j} .1467-9280.2007 .01964 . x$

Boynton, R. M. (1984). Psychophysics. In C. J. Bartleson \& F. Grum (Eds.), Optical radiation measurements: Vol. 5. Visual measurements (pp. 335-366). Orlando, FL: Academic Press.

Brainard, D. H. (1997). The Psychophysics Toolbox. Spatial Vision, 10, 433-436.

BRUCE, V., \& Young, A. (1986). Understanding face recognition. British Journal of Psychology, 7, 305-327.

Chiroro, P., \& Valentine, T. (1995). An investigation of the contact hypothesis of the own-race bias in face recognition. Quarterly Journal of Experimental Psychology, 48A, 879-894.

Chowdhry, O., Peterson, D. J., Lane, E., Leslie, D., Maclin, M. K., \& MacLin, O. H. (2008, March). Perceptual discontinuities in the perception of other race faces: Implications for examining the crossrace effect. Paper presented at the annual meeting of the American Psychology-Law Society, Jacksonville, FL.

Chowdhry, O., Peterson, D. [J.], MacLin, M. K., \& Maclin, O. H. (2007, November). Special image morphing techniques used to examine the effects of racial markers in racial categorization. Paper presented at the annual meeting of the Society for Computers in Psychology, Long Beach, CA.

Corneille, O., Huart, J., Becquart, E., \& Brédart, S. (2004). When memory shifts toward more typical category exemplars: Accentuation effects in the recollection of ethnically ambiguous faces. Journal of Personality \& Social Psychology, 86, 236-250. doi:10.1037/0022 $-3514.86 .2 .236$

Correll, J., Urland, G. R., \& Ito, T. A. (2006). Event-related potentials and the decision to shoot: The role of threat perception and cognitive control. Journal of Experimental Social Psychology, 42, 120-128. doi:10.1016/j.jesp.2005.02.006

DAVIS, J. A. (1963). Intellectual climates in 135 American colleges and universities: A study in "social psychophysics." Sociology of Education, 37, 110-128.

Dercole, K. L., \& Davenport, W. G. (1974). Social psychophysics: Measurement of attitudes toward violence. Perceptual \& Motor Skills, 38, $135-145$

Dixon, M. R., \& MacLin, O. H. (2003). Visual basic for behavioral psychologists. Reno, NV: Context Press.

FeCHNer, G. (1966). Elements of psychophysics (Vol. 1) (H. E. Adler, trans.; D. H. Howes \& E. G. Boring, Eds.). New York: Holt, Rinehart \& Winston. (Original work published 1860) doi:10.1037/11304-026

Finney, D. J. (1947). Probit analysis. Cambridge: Cambridge University Press.

Gescheider, G. A. (1997). Psychophysics: The fundamentals (3rd ed.). Mahwah, NJ: Erlbaum.

Golby, A. J., Gabrieli, J. D. E., Chiao, J. Y., \& Eberhardt, J. L. (2001). Differential responses in the fusiform region to same-race and otherrace faces. Nature Neuroscience, 4, 845-850. doi:10.1038/90565

HARLey, E. M., \& Loftus, G. R. (2000). MATLAB and graphical user interfaces: Tools for experimental management. Behavior Research Methods, Instruments, \& Computers, 32, 290-296.

Hart, A. J., Whalen, P. J., Shin, L. M., McInerney, S. C., Fischer, H., \& RAUCH, S. L. (2000). Differential response in the human amygdala to racial outgroup vs. ingroup face stimuli. NeuroReport, 11, 2351-2355.

InNocence Project (2008). The Innocence Project. Retrieved March 19, 2007, from www.innocenceproject.org/.

Ito, T. A., Thompson, E., \& CACIOPPO, J. T. (2004). Tracking the timecourse of social perception: The effects of racial cues on event-related 
brain potentials. Personality \& Social Psychology Bulletin, 30, 1267 1280. doi: $10.1177 / 0146167204264335$

JACKSON, J. M., \& LATANÉ, B. (1981). All alone in front of all those people: Stage fright as a function of number and type of co-performers and audience. Journal of Personality \& Social Psychology, 40, 73-85. doi:10.1037/0022-3514.40.1.73

Joshi, P., Peterson, D. J., MacLin, M. K., \& MacLin, O. H. (2007, November). A computerized system to examine the perception of race and skin tone using racial markers. Paper presented at the annual meeting of the Society for Computers in Psychology, Long Beach, CA.

Krantz, J. H., Ballard, J., \& Scher, J. (1997). Comparing the results of laboratory and World Wide Web samples on the determinants of female attractiveness. Behavior Research Methods, Instruments, \& Computers, 29, 264-269.

Kurzban, R. (2001). The social psychophysics of cooperation: Nonverbal communication in a public goods game. Journal of Nonverbal Behavior, 25, 241-259. doi:10.1023/A:1012563421824

LeVIN, D. T., \& BANAJI, M. R. (2006). Distortions in the perceived lightness of faces: The role of race categories. Journal of Experimental Psychology: General, 135, 501-512. doi:10.1037/0096-3445.135.4.501

MacLin, O. H. (2007, November). Psychophysical techniques examining the social psychology of race and racial identifications. Symposium presented at the annual meeting of the Society for Computers in Psychology, Long Beach, CA.

MacLin, O. H., Dixon, M. R., \& JACKson, J. W. (2007). Visual Basic 2005 for psychologists. Reno, NV: Context Press.

MacLin, O. H., \& MACLIN, M. K. (2007, November). Using PsychoPro to examine social psychological phenomena. Paper presented at the annual meeting of the Society for Computers in Psychology, Long Beach, CA.

MacLin, O. H., \& MacLin, M. K. (in press). The role of racial markers in race perception and racial categorization. In R. Adams, N. Ambady, K. Nakayama, \& S. Shimojo (Eds.), People watching: The social ecology of visual perception. Oxford: Oxford University Press.

MacLin, O. H., MacLin, M. K., \& Peterson, D. (2008, March). Crossracial identification and classification: A cognitive gating mechanism for faces. Paper presented at the annual meeting of the American Psychology-Law Society, Jacksonville, FL.

MacLin, O. H., \& MalPass, R. S. (2001). Racial categorization of faces: The ambiguous race face effect. Psychology, Public Policy, \& Law, 7, 98-118. doi:10.1037/1076-8971.7.1.98

MacLin, O. H., \& Malpass, R. S. (2003). The ambiguous-race face illusion. Perception, 32, 249-252. doi:10.1068/p5046

MacLin, O. H., \& Webster, M. A. (2001). The influence of adaptation on the perception of distortions in natural images. Journal of Electronic Imaging, 10, 100-109.

Malpass, R. S., \& Kravitz, J. (1969). Recognition for faces of own and other race. Journal of Personality \& Social Psychology, 13, 330-334. doi: $10.1037 / \mathrm{h} 0028434$

Meissner, C. A., \& Brigham, J. C. (2001). Thirty years of investigating the own-race bias in memory for faces: A meta-analytic review. Psychology, Public Policy, \& Law, 7, 3-35. doi:10.1037/1076-8971.7.1.3

Meltzer, L., Morris, W. N., \& Hayes, D. P. (1971). Interruption outcomes and vocal amplitude: Explorations in social psychophysics. Journal of Personality \& Social Psychology, 18, 392-402. doi:10.1037/ h0030993

Pelli, D. G. (1997). The VideoToolbox software for visual psychophysics: Transforming numbers into movies. Spatial Vision, 10, 437-442.

Phelps, E. A., O'Connor, K. J., Cunningham, W. A., Funayama,
E. S., Gatenby, J. C., Gore, J. C., \& Banaji, M. R. (2000). Performance on indirect measures of race evaluation predicts amygdala activation. Journal of Cognitive Neuroscience, 12, 729-738. doi: $10.1162 / 089892900562552$

Phelps, E. A., \& Thomas, L. A. (2003). Race, behavior, and the brain: The role of neuron imaging in understanding complex social behaviors. Political Psychology, 24, 747-758. doi:10.1046/j.1467 $-9221.2003 .00350 . \mathrm{x}$

Roby, T. B., \& Budrose, C. R. (1966). Psychophysical scale matching as a prototypical language task. Journal of Personality \& Social Psychology, 3, 675-684. doi:10.1037/h0023191

Smith, E. R., \& ZÁrate, M. A. (1990). Exemplar and prototype use in social categorization. Social Cognition, 8, 243-262.

SNODGRass, J. G. (1975). Psychophysics. In B. Scharf(Ed.), Experimental sensory psychology (pp. 17-67). Glenview, IL: Scott, Foresman.

Sporer, S. L. (2001). Recognizing faces of other ethnic groups: An integration of theories. Psychology, Public Policy, \& Law, 7, 36-97. doi:10.1037/1076-8971.7.1.36

Stern, S. E., Mullennix, J. W., Corneille, O., \& Huart, J. (2007). Distortions in the memory of the pitch of speech. Experimental Psychology, 54, 148-160. doi:10.1027/1618-3169.54.2.148

Stevens, S. S. (1936). A scale for the measurement of a psychological magnitude: Loudness. Psychological Review, 43, 405-416. doi:10.1037/h0058773

STEYVERS, M. (1999). Morphing techniques for manipulating face images. Behavior Research Methods, Instruments, \& Computers, 31, 359-369.

Thurstone, L. L. (1931). The measurement of social attitudes. American Journal of Sociology, 23, 529-544. doi:10.1037/h0070363

UpSHAw, H. S. (1962). Own attitude as an anchor in equal-appearing intervals. Journal of Abnormal \& Social Psychology, 64, 85-96. doi:10.1037/h0048600

Valentine, T., Chiroro, P., \& Dixon, R. (1995). An account of the own-race bias and the contact hypothesis in terms of a face space model of face recognition. In T. Valentine (Ed.), Cognitive and computational aspects of face recognition: Explorations in face space (pp. 69-94) London: Routledge.

WARD, J., \& LIU, C. H. (2005). VRVision: A new tool for the display of 3-D images in behavioral research. Behavior Research Methods, 37, 464-469.

Webster, M. A., Kaping, D., Mizokami, Y., \& Duhamel, P. (2004). Adaptation to natural facial categories. Nature, 428, 558-561. doi: $10.1038 /$ nature 02420

Wenderoth, P. (1990). Software-based visual psychophysics using the Commodore Amiga with Deluxe Paint III. Behavior Research Methods, Instruments, \& Computers, 22, 383-388.

Willadisen-Jensen, E. C., \& ITo, T. A. (2006). Ambiguity and the timecourse of racial perception. Social Cognition, 24, 580-606. doi:10.1521/soco. 2006.24 .5 .580

Wilson, P. R., \& RUSSELL, P. N. (1966). Modification of psychophysical judgments as a method of reducing dissonance. Journal of Personality \& Social Psychology, 3, 710-712. doi:10.1037/h0023238

ZÁrate, M. A., \& SMith, E. R. (1990). Person categorization and stereotyping. Social Cognition, 8, 161-185.

ZeBrowitz, L. A. (1998). Reading faces: Window to the soul? Boulder, CO: Westview Press.

(Manuscript received December 7, 2007; revision accepted for publication May 22, 2008.) 